\title{
THE BLOOD PYRUVIC ACID LEVEL IN RENAL DISEASES AND IN URAEMIC COMA*
}

\author{
BY \\ J. KLEEBERG AND S. GITELSON \\ From the Medical Department A, Rothschild Hadassah University Hospital, and the Hebrew University \\ Hadassah Medical School, Jerusalem, Israel
}

(RECEIVED FOR PUBLICATION JUNE 7, 1955)

In the course of investigating the blood pyruvic acid levels we examined, amongst others, comatose patients with renal failure due to chronic nephritis and found the level to be normal. This finding was in contrast with that of high blood pyruvic acid levels in patients in coma due to other causes, e.g., hepatic (Snell and Butt, 1941; Amatuzio and Nesbitt, 1950 ; Carfagno, De Horatius, and Schwarz, 1953 ; Kleeberg and Gitelson, 1953), diabetic (Meyer, 1948 ; Boulin and Meyer, 1949), cerebral (Gitelson and Tiberin, 1952), and seemed to be of diagnostic value. Therefore, the study of blood pyruvic acid concentration was extended to include a greater number of patients with renal diseases and also to patients with urological disorders liable to affect renal function.

\section{Methods}

Sixty patients were examined with the aim of ascertaining whether pure renal diseases alter the normal blood pyruvic acid level ; whether kidney diseases change the known response of the blood pyruvic acid level in other disorders; whether the blood pyruvic acid level in patients with uraemic coma is different from that in patients with other kinds of coma who do not exhibit signs of renal failure ; and whether hypertension, which is present in the majority of patients with nephritis, influences the blood ryruvic acid level by itself.

The patients were accordingly divided into four groups:

Group I.-This group consisted of 26 patients with renal or urological diseases but without additional disorders or complications known to cause a rise in blood pyruvic acid level, such as thromboembolism, cerebral accidents, pulmonary oedema, shock, severe liver damage, severe diabetes, or high fever.

The group included 16 patients with chronic glomerulonephritis, three of whom were in the nephrotic stage, and one with acute glomerulonephritis ; four cases of chronic pyelonephritis, four with chronic urinary infection complicating prostatic hypertrophy or urolithiasis, and pyelitis ; one with the Kimmelstiel-Wilson syndrome and $\stackrel{\sim}{-}$ compensated diabetes.

Sixteen patients in this group had renal insuffici- 0 ency with blood urea values ranging from 42 to $480 \mathrm{mg} . \%$. The majority of them had acidosis with $\bar{z}$ alkali reserve values as low as $16 \mathrm{vol} . \% \mathrm{CO}_{2}$. Eight patients were in coma or in a precomatose state.

Group II.-This group comprised five patients oु with both renal disease and complications. It included three cases of chronic glomerulonephritis, one with chronic pyelonephritis and one of cholaemic nephrosis following infectious hepatitis. Two of them suffered, in addition, from hypertensive $\frac{0}{\mathrm{O}}$ encephalopathy, one from massive cerebral haemor- $\stackrel{\varrho}{\rightarrow}$ rhage, and one from pulmonary oedema. The fifth $\overrightarrow{\overrightarrow{0}}$ patient, with cholaemic nephrosis, had signs of 3 severe liver damage. All five patients were comatose. Their blood urea levels ranged from 71 to $380 \mathrm{mg} . \%$, and their alkali reserve values from 49 to 7 vol. $\%$ 응 $\mathrm{CO}_{2}$.

Group III.-This group was made up of $14 \underline{3}$. comatose patients with no significant findings in the urine and with normal or almost normal blood urea values. It included eight patients in hepatic coma응 or precoma due to decompensated liver cirrhosis, $\rightarrow$ prolonged obstructive jaundice, or severe infectious hepatitis, and six patients in coma due to cerebral haemorrhage or embolism.

Group IV.-This group consisted of 15 patients 0 with essential hypertension without complications or N signs of marked renal damage. Their bloodo pressures ranged from $165 / 95$ to $220 / 130 \mathrm{~mm}_{\mathrm{O}}$ mercury.

The blood pyruvic acid level was determined in all@ these patients by the Friedemann-Haugen method 0 (Friedemann and Haugen, 1943) 12 hours after the last meal and during bed rest. In the majority of the patients the estimations were repeated at intervals. $\overrightarrow{\mathbb{Q}}$ Blood sugar levels were examined in almost allo

* Partly supported by the Hadassah Medical Organization Fund. 
TABLE I

BLOOD PYRUVIC ACID LEVELS IN RENAL DISEASE

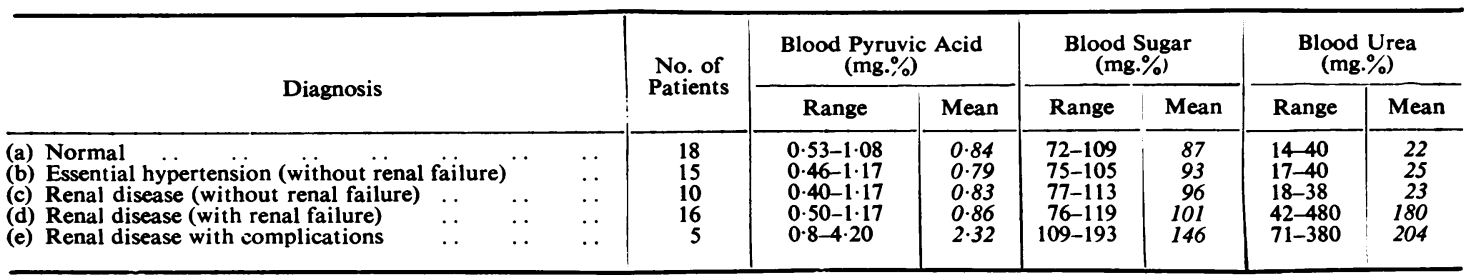

TABLE II

BLOOD PYRUVIC ACID LEVELS IN PATIENTS IN VARIOUS TYPES OF COMA

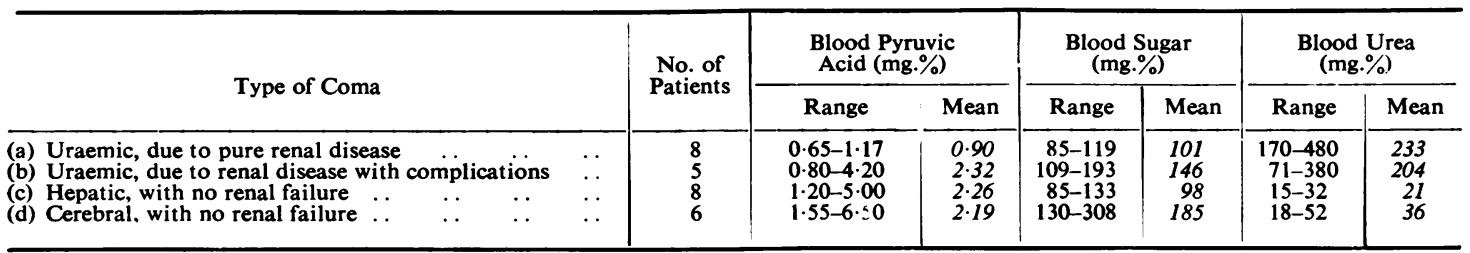

patients by the Folin-Wu method simultaneously with those of the blood pyruvic acid.

The urinary excretion of pyruvic acid was determined in five uraemic patients by the same method as used for estimations in blood.

The majority of patients with nephritis were on a diet rich in carbohydrates. However, because of the severe condition of some of them no attempt was made to maintain a standard diet for all. The patients received in addition $50 \mathrm{mg}$. of thiamine, and none showed signs of thiamine deficiency.

\section{Results}

Pyruvic Acid in Blood and Urine.-Nearly all patients with nephritis or chronic urinary infection with no additional acute complications (Group I) had normal blood pyruvic acid levels, i.e., between 0.5 and $1.1 \mathrm{mg} . \%$. This held true for patients with unimpaired renal function, as well as for those with renal failure and acidosis (Table $\mathrm{I}, \mathrm{c}, \mathrm{d})$. Even in moribund patients in uraemic coma and with alkali reserve values as low as $16 \mathrm{vol} . \% \mathrm{CO}_{2}$ the blood pyruvic acid was on the upper limit of normal (up to $1.17 \mathrm{mg} . \%$, Table II, a).

Only those five patients with renal disease who suffered from severe complications (Group II) had elevated blood pyruvic acid levels (up to $4.2 \mathrm{mg} . \%$ ), (Table I, e). But this rise was very slight in the patient with the cholaemic nephrosis $(1.2 \mathrm{mg} . \%)$.

In all patients in hepatic or cerebral coma, who had no signs of renal damage (Group III), the blood pyruvic acid level was elevated (up to $6.5 \mathrm{mg}$.\%; Table II, c, d).
All patients with essential hypertension who did not show signs of renal damage or complications (Group IV) had normal blood pyruvic acid levels (Table I, b).

The excretion of pyruvic acid in the urine determined in five uraemic patients was within normal limits ranging from 4 to $16 \mathrm{mg}$. per 24 hours (our normal values with an unsupervised diet were from 4 to $25 \mathrm{mg}$. ; unpublished data).

Glucose in Blood and Urine.-In patients with uncomplicated renal, urological and hypertensive diseases (Groups I and IV) and also in pure hepatic coma (Group III) the blood sugar values were mostly normal but occasionally slightly elevated (Tables I, c, d, and II, a, c). The values were markedly raised in almost all patients of Group II who had acute complications in addition to the renal disease (Table I, e) and in patients in coma of cerebral origin with no renal disease (Group III) (Table II, b, d).

Glycosuria was found at times only in one severely uraemic patient with pure renal disease, during intravenous infusion of glucose. It was found more often in patients with severe complications.

\section{Discussion}

Blood Pyruvic Acid and Renal Disease.-These experiments have shown that in all our patients with uncomplicated renal or urological disease, as well as in those with uncomplicated essential hypertension, the blood pyruvic acid was normal irrespective of the state of the renal function or the presence of acidosis. Only in those patients in whom renal 
insufficiency was accompanied by severe complications, known from previous studies to cause hyperpyruvicaemia, was the blood pyruvic acid level markedly elevated

Similar results have been reported previously by Davis and Bauer (1944) in a group of 11 patients with renal insufficiency. Their series included three cases of acute glomerulonephritis with normal blood pyruvic acid levels.

These studies seem to indicate that renal disease of itself does not raise the normal blood pyruvic acid level and, on the other hand, does not prevent such a rise when it is caused by other disorders. This finding is not surprising if one considers the role played by the kidneys in the pyruvic acid balance in the body.

There is ample experimental evidence that kidney tissue is able both to utilize and to form pyruvic acid (Peters and Van Slyke, 1946 ; Krebs, 1933, 1935 ; Bernheim, Bernheim, and Gillaspie, 1936 ; Braunstein and Kritzmann, 1937 ; Russell and Wilhelmi, 1941). However, the mass of the kidneys in relation to that of all other tissues able to form and to metabolize pyruvic acid is small, and it is conceivable that the share of the kidneys in the total pyruvic acid metabolism of the body is small. Hence, theoretically, a change in blood pyruvic acid levels should not be expected in patients with damaged kidneys, even in case their potential metabolic function is impaired.

The excretory role of the kidneys also seems to be of little importance for the regulation of the blood pyruvic acid level in the body. The normal excretion of pyruvic acid in the urine does not exceed 20-25 mg. per 24 hours (Friedemann, 1950 ; Kleeberg and Gitelson, 1954a). This amount appears to be small in comparison with the total quantity of pyruvic acid in the body. This quantity may be estimated roughly at $400 \mathrm{mg}$., if it is assumed that pyruvic acid, under normal conditions, is evenly distributed throughout the intra- and extra-cellular fluids, and if the normal blood pyruvic acid level is taken as $0.8 \mathrm{mg} . \%$. Should this figure for the total body pyruvic acid be correct it would mean that in a completely anuric patient it would take at least 20 days for the accumulated pyruvic acid to raise its level in the blood $100 \%$, provided it is not metabolized by the body. It may be concluded therefore that an eventual decrease in pyruvic acid excretion due to renal failure and oliguria will not raise its level in the blood significantly. On the other hand, the normal figures for pyruvic acid excretion obtained in our uraemic patients suggest that renal damage does not increase this excretion (due to impaired tubular reabsorption) either.
Blood Pyruvic Acid and Blood Sugar in Renal Disease.-It is known that the blood level of pyruvic acid, a central intermediary product in the metabolism of the three main foodstuffs, rises when this metabolism is severely disturbed, e.g., in severe pancreatic and steroid diabetes (Meyer, 1948 ; Boulin and Meyer, 1949 ; Hills, Power, and Wilder, 1952 ; Kerppola, 1953), in hepatic failure (Snell and Butt, 1941; Amatuzio and Nesbitt, 1950 ; Carfagno et al., 1953; Kleeberg and Gitelson, 1953), in anoxia (Friedemann, Haugen, and Kmieciak, 1945), in severe heart failure (Barenghi, Belloti, and Scafidi, 1941 ; Yanof, 1942 ; Kleeberg and Gitelson, 1954b), in shock (Elliott, Rivers, Elliott, and Platt, 1941 ; Allison, Cole, Leathem, Nastuk, and Anderson, 1943 ; Russell, Long and Engel, 1944 ; Beatty, 1945), and in other disorders associated with severe stress (Selye, 1950).

In our patients with uncomplicated renal disease, even in those with severe renal failure, there were no instances of fasting hyperglycaemia or glycosuria which would indicate gross disturbances in carbohydrate metabolism. Therefore, the normal blood pyruvic acid levels found in these patients can be explained also on the basis of the absence of such disturbances originating outside the kidneys.

Of course the tests employed by us and the number of the patients examined are not sufficient to decide whether the carbohydrate metabolism in renal disease is impaired. In fact, several authors did find glycosuria, hyperglycaemia, and high and delayed glucose tolerance curves in a proportion of patients with nephritis (see review by Linder, Hiller, and Van Slyke, 1925). But the various authors had different opinions as to the frequency of these disturbances. Furthermore it is feasible that in 8 certain cases the mentioned disturbances were the direct result of additional disorders, such as latent 0 diabetes, hypertensive encephalopathy, cardiac failure, adrenal tumours, etc.

In our Group II there were four such patients in whom the renal disease was accompanied by severe 0 complications, and these were the only uraemic $N$ patients who had marked hyperglycaemia and hyperpyruvicaemia. We regarded this rise in the blood pyruvic acid level as a "stress" phenomenon not related to the kidney disease. This phenomenon $\stackrel{0}{\Phi}$ could be explained, like that in other conditions of $\stackrel{\oplus}{+}$ severe stress, in terms of increased katabolism 0 produced with the participation of adrenal medullary 0 and cortical hormones (Gitelson, 1953, 1954), of $\stackrel{\mathbb{Q}}{\overparen{Q}}$ hypoxia and liver damage.

Pyruvic Acid and Renal Acidosis.-The acidosis in renal insufficiency is caused chiefly by loss of base and retention of sulphate and phosphate ions. 
The concentration of organic acids in the blood is also increased in the advanced state of uraemia. However, there is no agreement as to the type of the acids involved (see Volhard, 1931 ; Fishberg, 1954). Aromatic oxyacids, phenols, amino-acids (Becher, 1924, 1925, 1926), and some unknown acids, products of protein metabolism (Straub, 1924), have all been incriminated. Peters, Wakeman, Eisenman, and Lee (1929) have shown that betaketoacids-and Jervell (1929) that lactic acid-may accumulate in the terminal stages of uraemia.

In those of the uraemic patients who had no complications, even a considerable drop in alkali reserve was not accompanied by a rise in blood pyruvic acid level. Hence, the ion of this alphaketoacid was not involved in the reduction of the concentration of the bicarbonate ion in the blood.

Pyruvic Acid in Patients with Various Kinds of Coma.-The previously described difference in the levels of the blood pyruvic acid in patients with pure uraemic coma (normal values) and in those with cerebral or hepatic coma (high values) is illustrated by Fig. 1. These differences suggest that, if a rise in

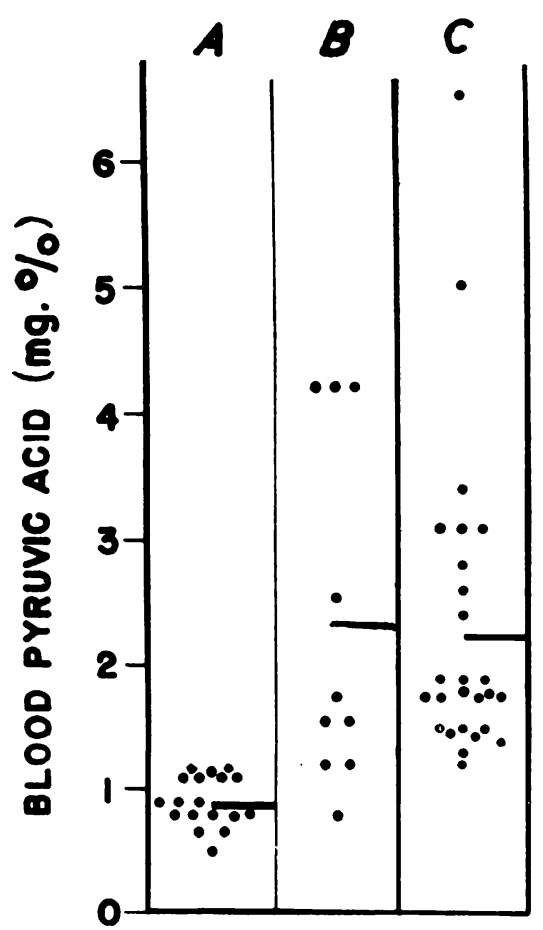

FIG. 1-Blood pyruvic acid levels in coma of different aetiology.

A. Patients with pure uraemic coma-normal values.

B. Patients in uraemic coma and with severe complicationselevated values.

C. Patients with cerebral or hepatic coma without signs of renal insufficiency —elevated values. blood pyruvic acid is found in a comatose patient with signs of renal damage, this rise should be attributed to a non-renal disorder or complication known to cause hyperpyruvicaemia (vide supra).

In patients with hepatorenal disturbances but with no other complications, a rise in blood pyruvic acid would indicate severe liver damage, while a lack of hyperpyruvicaemia would suggest that the liver damage is not very severe, since only severe liver damages raises the blood pyruvic acid level. The following case (included in Group II) illustrates this point :

A young student was admitted to this hospital in a state of confusion after having been taken sick a week before with nausea, vomiting, and fever. He later developed signs of infectious hepatitis with jaundice. He subsequently went into coma and died on the eighth day after admission. During the last five days he became anuric, oedema developed, and the blood urea level rose gradually to $380 \mathrm{mg} \%$. The urine contained albumin and granular casts. The blood pyruvic acid levels determined two days and one day before death were only slightly elevated $(1.2 \mathrm{mg} . \%)$. On the basis of this finding we presumed that the liver damage was not very severe, and that the uraemia was mainly responsible for the severity of the clinical picture. In fact, the necropsy revealed signs of healing hepatitis, in which the blood pyruvic acid level is usually not elevated, and there were found signs of bile nephrosis.

\section{Summary}

The determination of blood pyruvic acid levels revealed normal values in 24 out of 26 patients with uncomplicated chronic nephritis and chronic urinary infection regardless of whether the renal function was impaired or not. Even in patients with uraemic coma and severe acidosis the blood pyruvic acid was at most at the upper limit of normal.

The blood sugar values were normal in these patients and no glycosuria was found.

Normal blood pyruvic acid and blood sugar values were also found in 15 patients with essential hypertension who had no signs of renal damage or complications.

Elevated blood pyruvic acid levels were obtained only in those four patients with renal disease who, in addition, had severe complications, such as cerebral haemorrhage, hypertensive encephalopathy, or pulmonary oedema. The hyperpyruvicaemia in them was accompanied by hyperglycaemia and was regarded as a "stress" phenomenon.

Hyperpyruvicaemia was also present in six patients with cerebral coma and in eight patients with hepatic coma who had no signs of renal insufficiency. 
The excretion of pyruvic acid in the urine in five uraemic patients was within normal limits.

It is concluded that renal disease per se is unlikely to influence the blood pyruvic acid level. When hyperpyruvicaemia occurs in patients with renal disease, especially in those in coma, it is presumed to be due to some other disorder known to cause hyperpyruvicaemia. The level of the pyruvic acid in the blood may be of aid in the differential diagnosis of various types of coma.

Pyruvic acid seems not to be a causative factor in renal acidosis.

\section{REFERENCES}

Allison, J. B., Cole, W. H., Leathem, J. H., Nastuk, W. L., and Anderson, J. A. (1943). J. biol. Chem., 147, 255.

Amatuzio, D. S., and Nesbitt, S. (1950). J. clin. Invest., 29, 1486

Barenghi, G., Belotti, R., and Scafidi, C. (1941). Sez. Clin. Scient., 5. Beatty, C. H. (1945). Amer. J. Physiol., 143, 579.

Becher, E. (1924, 1925, 1926). Quoted by Volhard, F. (1931). Handbuch der inneren Medizin, 2nd ed., vol. 6, teil 1, pp. 757-8, 764. Springer, Berlin.

Bernheim, F., Bernheim, M. L. C., and Gillaspie, A. G. (1936). J. biol. Chem., 114, 657 .

Boulin, R., and Meyer, F. W. (1949). Quoted by Markees, S. (1950). Helv. med. Acta, ser. A, 17, 537.

Braunstein, A. E., and Kritzmann, M. G. (1937). Enzymologia, 2, 129.

Carfagno, S. C., De Horatius, R. F., and Schwarz, H. P. (1953). New Engl. J. Med., 249, 303.
Davis, H. A., and Bauer, F. K. (1944). Arch. Surg. (Chicago), 48 193.

Elliott, K. A. C., Rivers, T. D., Elliott, F. H., and Platt, B. (1941) J. Lab. clin. Med., 26, 1928

Fishberg, A. M. (1954). Hypertension and Nephritis, 5th ed., pp. 6669. Lea and Febiger, Philadelphia.

Friedemann, T. E. (1950). Personal communication.

- and Haugen, G. E. (1943). J. biol. Chem., 147, 415.

- and Kmieciak, T. C. (1945). Ibid., 157, 673.

Gitelson, S. (1953). Acta med. scand., 146, 98. (1954). Acta endocrinol., 15, 225.

- and Tiberin, P. (1952). Ibid 11, 345.

Hill and Tiberin, P. (1952). Ibid., 11, 345. s, O. W., Power, M. H., and Wilder, R. M. (1952). Diabetes, 1, ڤ

Jervell, O. (1929). Quoted by Volhard, F. (1931). Handbuch der $\overrightarrow{0}$ inneren Medizin, 2nd ed., vol. 6, teil 1, p. 764. Springer, Berlin.

Kerppola, W. (1953). Acta med. scand., 145, 357.

Kleeberg, J., and Gitelson, S. (1953). Harefuah, 45, $152 . \quad$ (Eng. summary, p. 154.)

- (1954a). Unpublished data.

- (1954b). Journal of Clinical Pathology, 7, 116.

Krebs, H. A. (1933). Z. physiol. Chem., 217, 191.

- (1935). Biochem. J., 29, 1620.

Linder, G. C., Hiller, A., and Van Slyke, D. D. (1925). J. clin. î Invest., 1, 247.

Meyer, F. W. (1948). Quoted by Merkees, S. (1950). Helv. med. $\overrightarrow{\vec{D}}$ Acta, ser. A, 17, 537

Peters, J. P., and Van Slyke, D. D. (1946), Quanitative Clinical 은 Chemistry, Interpretations, vol. I, pp. 97-295. Williams \& Wilkins, Baltimore.

Wakeman, A. M., Eisenman, A. J., and Lee, C. (1929). J. clin. Z Invest., 6, 551 .

Russell, J. A., and Wilhelmi, E. (1941). J. biol. Chem., 140, 747.

- Long, C. N. H., and Engel, F. L. (1944). J. exp. Med., 79, 1. Selye, H. (1950). Stress. Acta, Montreal, Canada.

Snell, A. M., and Butt, H. R. (1941). Trans. Ass. Amer. Phys., 56 321 .

Straub, H. (1924). Ergebn. inn. Med. Kinderheilk, 25, 137

Volhard, F. (1931). Handbuch der inneren Medizin, 2nd ed. vol. 6, teil 1, pp. 714-791. Springer, Berlin.

Yanof, Z. A. (1942). Arch. intern. Med., 69, 1005. 